\title{
CURRICULA DE LOS AUTORES
}

Andrea Cucina. Italiano. Doctor en Paleopatología por la Escuela de Medicina de la Universidad Católica de Roma, Italia, actualmente adscrito a la Facultad de Ciencias Antropológicas de la Universidad Autónoma de Yucatán. Sus principales intereses de investigación son la antropología dental de poblaciones arqueológicas, la biología del esqueleto y los marcadores de prácticas biológicas y culturales en éste. Entre sus últimos artículos, todos en coautoría, se encuentran "Trace-Element Evidence for Foreigners at a Maya Port in Northern Yucatan", "Salud oral y caries entre los mayas del período Clásico" y "Carious Lesions and Maize Consumption Among the Pre-Hispanic Maya: An Analysis of a Coastal Community in Northern Yucatan”.

acucina@yahoo.com

Caroline Cunill. Francesa. Doctora en Historia de América por la Universidad de Toulouse II-Le Mirail. Entre 2013 y 2014 realizó un posdoctorado en el Instituto de Investigaciones Históricas de la Universidad Nacional Autónoma de México, con el proyecto de investigación: "La institucionalización del oficio de intérprete en los tribunales novohispanos: justicia e interpretación en sociedades multilinguies". Actualmente es profesora de tiempo completo en la Université du Maine. Sus principales líneas de investigación son la relación entre instituciones coloniales y justicia indígena, el uso de la cultura jurídica por los mayas de Yucatán y el papel de los intermediarios en los procesos legales. Entre sus últimas publicaciones pueden citarse Los defensores de Indios de Yucatán y el acceso de los mayas a la justicia colonial, 1540-1600, "La negociación indígena en el Imperio ibérico: aportes a su discusión metodológica” y "Fray Bartolomé de las Casas y el oficio de defensor de indios en América y en la Corte española”.

cunillcaroline@gmail.com

Canek Estrada Peña. Mexicano. Licenciado en Estudios Latinoamericanos por la Facultad de Filosofía y Letras de la Universidad Nacional Autónoma de México, y maestro en Estudios Mesoamericanos por la misma universidad. En el año de 2011 se hizo merecedor al Premio Palenque. Entre sus últimas publicaciones se encuentran "Ri Juyub', ri q'aq', ri nuch ("El cerro, el fuego, el bebé”): acerca de la presentación de un niño k'iche' ante el mundo", "Ideas del tiempo cíclico en la cuenta de 260 días entre los k’iche' contemporáneos. El ciclo ritual del día 8 B’atz' " y "Lugares sagrados de los mayas de Guatemala: otra manera de pensar el patrimonio cultural", los dos primeros impresos, el último electrónico.

ajawcanek@yahoo.com.mx 
Lars Frühsorge. Alemán. Doctor en Estudios de Mesoamérica por la Universidad de Hamburgo, adscrito al Museo de Antropología de Luebeck. Sus intereses particulares son la etnohistoria y la etnografía de Guatemala, especialmente la religión maya, las tradiciones orales, los conceptos de tiempo e historia y el papel del patrimonio arqueológico en la cultura maya contemporánea. Su actual proyecto de investigación consiste en una comparación intercultural entre la historia colonial y la moderna de los mayas de Guatemala y México enfocándose en la evolución del sincretismo religioso, el activismo cultural y el desarrollo de una identidad pan-indígena en ambas regiones. Entre sus últimas publicaciones se encuentran "Salt, Sites, and 'Mythology': Cultural Memory in San Mateo Ixtatán (Huehuetenango, Guatemala) from Pre-Hispanic to Modern Times", Archäologisches Kulturerbe, lokale Erinnerungskultur und jugendliches Geschichtsbewusstsein bei den Maya: Eine historische und ethnographische Untersuchung indigener Interpretationen der vorspanischen Zeit, der spanischen Invasion und des Bürgerkriegs in Guatemala y "Maximón: un santo milagroso, incluso en Hamburgo".

lars@fruehsorge.de

Ana García Barrios. Española. Doctora en Antropología de América por la Universidad Complutense de Madrid. Profesora titular interina de la Universidad Rey Juan Carlos de Madrid desde 2008. Ha participado en diversos proyectos arqueológicos del área maya en México (Oxkintok, Chichén Itzá, Calakmul). Sus áreas de especialización son la iconografía, religión y política mayas, sobre las cuales ha escrito cuatro libros y diversos capítulos de libros y artículos. Entre los más recientes de estos últimos se cuentan "El aspecto bélico de Chaahk, el dios de la lluvia maya en el Periodo Clásico" (2009), "Dioses del Cielo, dioses de la Tierra", "Moda y protocolo en el reino de Kaan, siglo vil d.C." y "Difusión de dioses como modelo de refuerzo en el control político. El caso del reino de Kan'ul y Chaahk".

ana.barrios@urj.es

María del Carmen León Cázares. Mexicana. Doctora en Historia por la Facultad de Filosofía y Letras de la Universidad Nacional Autónoma de México. Investigadora titular del Centro de Estudios Mayas del Instituto de Investigaciones Filológicas de la Universidad Nacional Autónoma de México y profesora en la Facultad de Filosofía y Letras de la misma universidad. Sus líneas de investigación son la historia y la historiografía del área maya bajo la dominación española. La mayor parte de sus publicaciones se ha centrado en la construcción de una historia de la historiografía de los pueblos mayas. Muestra de ello son la edición que realizó de la Relación de las cosas de Yucatán de Diego de Landa, el estudio referente al mismo Landa en el volumen I de la Historiografía Mexicana, y el ensayo "Un encuentro historiográfico peninsular entre un fraile franciscano y un editor liberal", en el libro Ideas, ideólogos e idearios en la construcción de la imagen peninsular, donde da a conocer avances realizados en el análisis de la obra de Diego López Cogolludo. Tuvo asimismo a 
su cargo los estudios referentes a "Diego de Landa", "Pedro Mártir de Anglería", "Gonzalo Fernández de Oviedo" y "Francisco López de Gómara" en la obra colectiva Historiografía mexicana.

carmenleoncazares@yahoo.com.mx

Matthew G. Looper. Estadounidense. Doctor en Historia del Arte por la Universidad de Texas en Austin, adscrito al Departamento de Arte e Historia del Arte de la Universidad del Estado de California en Chico, California. Especialista en epigrafía e iconografía, desarrolla actualmente una investigación sobre el cambio histórico de la escritura maya. Entre sus últimas publicaciones como autor único se encuentran "Dance, Power, and Ideology in Aztec and Maya Society", To Be Like Gods: Dance in Ancient Maya Civilization y "Lightning is Born: Using Ch'orti' Ritual to Interpret Ancient Maya Art".

mlooper@csuchico.edu

Mallory E. Matsumoto. Estadounidense. Cursó dos licenciaturas: en Filología alemana y en Arqueología. Concluyó sus estudios de maestría en el programa de Linguíística General y Filología Comparativa en la Universidad de Oxford, y cursa otra maestría en el programa de Antropología de las Américas en la Universidad de Bonn. Durante sus estudios de arqueología participó en el proyecto sobre análisis de cerámica de artefactos del noroeste de Honduras. En 2014 excavó con el grupo del Proyecto Arqueológico Uxul en Uxul, Campeche, México. Actualmente trabaja en el proyecto Diccionario Interdisciplinario del Maya Clásico (IDIOM) de la Universidad de Bonn. Entre sus últimas publicaciones se encuentran "Reflection as Transformation: Mirror-Image Structure on Maya Monumental Texts as a Visual Metaphor for Ritual Participation" y "Divine Intervention: Invocations of Deities in Personal Correspondence from Graeco-Roman Egypt".

mem348@uni-bonn.de

Joel Palka. Estadounidense. Doctor en Antropología por la Universidad de Vanderbilt, Estados Unidos, y licenciado en Antropología por la Universidad de Noroeste de Illinois, Estados Unidos. Actualmente labora como profesor titular en la Universidad de Illinois en Chicago. Su obra se centra en la antigua ritualidad maya y en la etnohistoria y la arqueología colonial de grupos lacandones de Chiapas y Guatemala. Sus publicaciones recientes incluyen Unconquered Lacandon Maya: Ethnohistory and Archaeology of Indigenous Culture Change, Maya Pilgrimage to Ritual. Landscapes: Insights from Archaeology, History, and Ethnography y Classic Maya Social. Inequality and the Collapse at Dos Pilas, Petén, Guatemala.

jpalka@uic.edu

Vera Tiesler. Mexicana. Doctora en Antropología por la Universidad Nacional Autónoma de México. Adscrita a la Facultad de Ciencias Antropológicas de la Universidad Autónoma de Yucatán. Miembro de la Academia Mexicana de Ciencias 
y nivel III del Sistema Nacional de Investigadores. Su obra se centra en la bioarqueología, la tafonomía y las prácticas mortuorias entre los mayas prehispánicos y coloniales. Entre sus publicaciones recientes se cuentan Transformarse en maya. El modelado cefálico entre los mayas prehispánicos y coloniales, la coedición de Orígenes de la sociedad campechana. Vida y muerte en la ciudad de Campeche durante los siglos xVI y XVII y The Bioarchaeology of Artificial Cranial Modifications. New Approaches to Head Shaping and its Meanings in Pre-Columbian Mesoamerica and Beyond.

$$
\text { vtiesler@yahoo.com }
$$

Gabrielle Vail. Estadounidense. Doctora en Antropología por la Universidad de Tulane. Adscrita a la División de Ciencias Sociales del New College of Florida; sus especialidades son la epigrafía y los códices mayas. Su actual proyecto de investigación se aboca al estudio de deidades y mitologías en las Tierras Bajas Mayas del norte durante los períodos Clásico Tardío y Terminal. Entre sus últimas publicaciones se encuentran Códice de Madrid, Re-Creating Primordial. Time: Foundation Rituals and Mythology in the Postclassic Maya Codices y "Rain and Fertility Rituals in Postclassic Yucatán Featuring Chaak and Chak Chel”, estas últimas en coautoría con Christine Hernández.

gvail@ncf.edu 